\title{
Is the Glass Half Full or Half Empty?
}

\author{
Gerbrich E. van den Bosch ${ }^{a}$ Tonya White ${ }^{b, d}$ Dick Tibboel ${ }^{a} \quad$ Monique van Dijk $^{a, c}$ \\ antensive Care and Department of Pediatric Surgery, ${ }^{\mathrm{b}}$ Department of Child and Adolescent Psychiatry/Psychology, \\ and 'Division of Neonatology, Department of Pediatrics, Erasmus MC-Sophia Children's Hospital, and \\ dDepartment of Radiology, Erasmus MC, Rotterdam, The Netherlands
}

Dear Sir,

We thank Holsti and colleagues for their comments on our findings. Indeed, as they summarized, we found significant correlations (range 0.60-0.85) between specific brain volumes and important clinical variables such as gestational age, number of painful procedures and morphine exposure. However, there were no significant correlations between these variables and brain functioning as reflected by thermal sensitivity. Likewise, we found no differences between case subjects and healthy controls with respect to detection and pain thresholds. We were specifically interested in thermal sensitivity and neuropsychological functioning, as in several animal studies pain sensitivity and cognition were negatively associated with neonatal pain and opioid exposure.

Neuropsychological outcome was indeed moderately but significantly correlated with morphine exposure, as reflected by 2 out of the 15 NEPSY test scores: number of 'Commission Errors' in the subtest 'Response Set' and total score for 'Recognition' in the subtest 'Narrative Memory'. However, the direction of one of these correlations was different from how Holsti and colleagues interpret this. Number of 'Com- mission Errors' had a correlation coefficient of -0.46 with morphine exposure $(p=0.05)$, i.e. a higher exposure to morphine was associated with a lower number of errors. The other significant correlation of -0.46 indicates that children with morphine exposure performed worse on the subtest 'Recognition'. So, out of 15 NEPSY test scores, higher morphine exposure was associated with a worse performance in only 1 test score. Interestingly, none of the 15 test scores was significantly correlated to gestational age or number of painful procedures. The most important findings with regard to these children's neuropsychological functioning are that overall they scored 'average' and that there were no statistically significant differences in neuropsychological functioning between the case subjects and healthy controls.

Indeed, only 11 out of 19 children successfully completed MRI scanning. Children were excluded not only because of poor image quality, but also because of MRI contraindications (e.g. placement of a clip in cardiac surgery). The mean cumulative dose of morphine given in the first 28 days of life was $973 \mu \mathrm{g} / \mathrm{kg}$ (SD 1,447) in those 11 children versus 886 (SD 1,268) in the 8 excluded children (nonsignificant: $\mathrm{p}=0.89$ ). Three of the 11 children included in the MRI analyses did not receive morphine in the first 4 weeks of life. In table 1, we present all the raw data on the brain volumes per child included in the MRI analyses as well as the distribution of morphine exposure. Since many children are referred to a peripheral hospital after weeks of care in an academic hospital, we present only the morphine exposure in the first 28 days of life to circumvent bias due to missing data. Moreover, it is thought that neonatal pain and opioid exposure in the first weeks of life would have the most detrimental effects in the long term since the brain is rapidly developing in this period.

We presented a sample of preterm children in a range reflecting the clinical situation rather than including only children born extremely preterm or born with an extremely low birth weight. In addition, $10 \mu \mathrm{g} / \mathrm{kg} / \mathrm{h}$ is not a low dose in Europe, but was the standard prescribed dosage at the time of our study. Based on previous pharmacokinetic and pharmacodynamic studies, we have even started to use lower doses in, for example, postoperative care $[1,2]$.

\section{KARGER}

E-Mail karger@karger.com

www.karger.com/neo (c) 2015 S. Karger AG, Base

1661-7800/15/1092-0122\$39.50/0
Gerbrich E. van den Bosch, MD, PhD

Erasmus MC-Sophia Children's Hospital Room KP-2881, PO Box 2060

NL-3000 CB Rotterdam (The Netherlands)

E-Mail g.vandenbosch@erasmusmc.nl 
Table 1. Global brain volumes and volumes of pain-related brain regions per case $(\mathrm{n}=11$ cases)

\begin{tabular}{|c|c|c|c|c|c|c|c|c|c|c|c|c|c|c|c|c|c|c|c|}
\hline \multirow{3}{*}{$\begin{array}{l}\text { Morphine, } \\
\mu \mathrm{g} / \mathrm{kg}\end{array}$} & \multicolumn{19}{|c|}{ Brain volumes, $\mathrm{cm}^{3}$} \\
\hline & \multirow[t]{2}{*}{$\begin{array}{l}\text { total brain } \\
\text { volume }\end{array}$} & \multirow[t]{2}{*}{$\begin{array}{l}\text { cerebral } \\
\text { WM }\end{array}$} & \multirow{2}{*}{$\begin{array}{l}\text { total } \\
\text { gray } \\
\text { volume }\end{array}$} & \multicolumn{2}{|c|}{$\begin{array}{l}\text { parietal } \\
\text { lobe }\end{array}$} & \multicolumn{2}{|c|}{$\begin{array}{l}\text { frontal } \\
\text { lobe }\end{array}$} & \multicolumn{2}{|c|}{$\begin{array}{l}\text { cerebellum } \\
\text { WM }\end{array}$} & \multicolumn{2}{|c|}{$\begin{array}{l}\text { cerebellum } \\
\text { cortex }\end{array}$} & \multicolumn{2}{|c|}{ thalamus } & \multicolumn{2}{|c|}{ amygdala } & \multicolumn{2}{|c|}{ ACC } & \multicolumn{2}{|c|}{ insula } \\
\hline & & & & left & right & left & right & left & right & left & right & left & right & left & right & left & right & left & right \\
\hline 0 & 1,129 & 370 & 697 & 71 & 70 & 96 & 97 & 15 & 14 & 61 & 60 & 7.7 & 7.2 & 1.6 & 1.8 & 1.8 & 2.9 & 7.6 & 7.1 \\
\hline 0 & 1,176 & 406 & 739 & 75 & 74 & 107 & 108 & 12 & 12 & 53 & 53 & 6.6 & 7.0 & 1.9 & 1.8 & 1.4 & 2.9 & 8.1 & 8.3 \\
\hline 0 & 1,200 & 396 & 756 & 76 & 78 & 112 & 109 & 15 & 16 & 64 & 66 & 7.0 & 7.1 & 1.5 & 1.7 & 2.2 & 2.9 & 5.9 & 6.1 \\
\hline 135 & 1,177 & 395 & 733 & 72 & 74 & 113 & 109 & 14 & 13 & 57 & 56 & 6.1 & 5.8 & 1.9 & 1.8 & 2.0 & 3.3 & 6.5 & 6.7 \\
\hline 240 & 1,299 & 424 & 818 & 89 & 85 & 121 & 121 & 15 & 15 & 60 & 60 & 6.8 & 7.0 & 1.8 & 1.8 & 1.9 & 2.9 & 7.4 & 6.9 \\
\hline 394 & 1,238 & 411 & 760 & 81 & 86 & 108 & 100 & 14 & 16 & 54 & 56 & 7.5 & 7.4 & 1.1 & 1.3 & 1.9 & 2.2 & 7.7 & 7.7 \\
\hline 714 & 1,094 & 364 & 696 & 69 & 73 & 104 & 104 & 10 & 11 & 53 & 52 & 6.0 & 6.4 & 1.4 & 1.4 & 2.7 & 2.1 & 7.1 & 6.8 \\
\hline 993 & 1,150 & 364 & 750 & 71 & 80 & 109 & 107 & 13 & 12 & 59 & 61 & 7.0 & 8.0 & 1.6 & 1.6 & 1.9 & 3.2 & 6.7 & 6.6 \\
\hline 1,320 & 1,045 & 340 & 669 & 65 & 68 & 97 & 102 & 11 & 11 & 55 & 56 & 6.7 & 5.8 & 1.7 & 1.7 & 2.3 & 1.8 & 6.3 & 6.4 \\
\hline 2,030 & 1,011 & 334 & 644 & 67 & 64 & 99 & 89 & 12 & 12 & 58 & 61 & 6.1 & 5.6 & 1.6 & 1.5 & 2.2 & 2.5 & 7.1 & 6.4 \\
\hline 4,873 & 904 & 284 & 587 & 60 & 62 & 89 & 85 & 10 & 11 & 44 & 46 & 4.8 & 5.3 & 1.4 & 1.4 & 1.8 & 2.6 & 6.1 & 5.5 \\
\hline
\end{tabular}

$\mathrm{WM}=$ White matter. $\mathrm{ACC}=$ anterior cingulate cortex.

We believe that prematurity, opioid exposure and neonatal pain may have important consequences for brain morphology, and the crucial issue in this regard is whether only the brain structures are affected or brain function as well? Based on our findings, we would like to see the glass half full rather than half empty; in this small group of children born preterm with a history of NICU admission, brain morphology was negatively correlated to prematurity, opioid exposure and neonatal pain, whereas brain function was not, suggesting that there are no major clinically relevant effects of prematurity, opioid exposure and neonatal pain. Larger studies are needed of course to confirm our findings.

\section{References}

1 Ceelie I, de Wildt SN, van Dijk M, et al: Effect of intravenous paracetamol on postoperative morphine requirements in neonates and infants undergoing major noncardiac surgery: a randomized controlled trial. JAMA 2013;309: 149-154.

2 Knibbe CA, Krekels EH, van den Anker JN, et al: Morphine glucuronidation in preterm neonates, infants and children younger than 3 years. Clin Pharmacokinet 2009;48:371-385. 